\title{
Prevalence of hearing impairment among school children in the Gampaha District of Sri Lanka
}

\author{
*Priyantha Julian Perera ${ }^{1}$, Anuradini Kasthurirathne ${ }^{1}$, Sumudu Sakalasuriya ${ }^{1}$ \\ Sri Lanka Journal of Child Health, 2021; 50(4): 617-621 \\ DOI: http://doi.org/10.4038/sljch.v50i4.9850
}

\begin{abstract}
Background: Normal hearing in a child is vital for acquisition of language skills, literacy, educational achievements, socialization and overall school performances. Globally, data on prevalence of childhood hearing impairment (HI) is sparse and Sri Lanka is not an exception.
\end{abstract}

Objectives: To describe the prevalence of $\mathrm{HI}$ among Sri Lankan school children and to assess the feasibility and effectiveness of a screening programme.

Method: A descriptive cross sectional study was conducted in the Gampaha district, covering all educational zones. Screening for HI, in randomly selected 984 students was carried out at schools using otoscopy, pure tone audiometry and otoacoustic emission. Children who failed at least one screening test were invited for a diagnostic testing carried out at the Faculty of Medicine, Ragama.

Results: Out of 984 students, 270 (27.4\%) failed one or more screening tests. Out of this 199 children $73.7 \%$ turned up for the diagnostic testing and $40(20.1 \%)$ were diagnosed to have HI. Minimal or mild HI was present in $32(80 \%)$, three (7.5\%) had severe and another three (7.5\%) had profound HI. With correction for the children who defaulted the diagnostic test, prevalence of all types $\mathrm{HI}$ in this student population was $5.5 \%$.

Conclusions: In this student population in the Gampaha district, prevalence of all types HI was

${ }^{1}$ Professor in Paediatrics, ${ }^{2}$ Lecturer, Department of Paediatrics, Faculty of Medicine, University of Kelaniya, Sri Lanka, ${ }^{3}$ Professor in Public Health, Department of Public Health, Faculty of Medicine, University of Kelaniya, Sri Lanka

*Correspondence: priyanthaprr@gmail.com

D. https://orcid.org/0000-0001-9127-0329

(Received on 10 October 2020: Accepted after revision on 20 November 2020)

The authors declare that there are no conflicts of interest.

Funding: Research grant received from the University of Kelaniya, Sri Lanka.

Open Access Article published under the Creative Commons Attribution CC-BY c) (i) License
$5.5 \%$. The HI was mild in $80 \%$, severe in $7.5 \%$ and profound in $7.5 \%$.

(Key words: Hearing impairment, School children, Screening)

\section{Introduction}

Normal hearing is essential for acquisition of language skills. Hearing impairment (HI) not detected and corrected early, will result in language deficits with significant impact on literacy, educational achievements, socialization, and overall school performances ${ }^{1}$. Prevalence of HI varies from country to country, and disabling $\mathrm{HI}$ among children is greatest in South Asia, Asia Pacific and Sub-Saharan Africa ${ }^{2}$. Even minimal undetected HI can adversely affect the academic performance of a child, and HI resulting from repeated ear infections interfere with language development ${ }^{3}$.

Hearing is generally assessed at $0.5,1,2$ and 4 $\mathrm{kHz}$, which corresponds to the normal speech frequencies ${ }^{4}$. Level of hearing of an individual is described in decibels (DB). A method of classifying HI was described by Clark JG, in $1981^{5}$. Accordingly, hearing level of a normal individual is -10 to +15 . Hearing level between $16-25 \mathrm{~dB}$ is minimal HI and mostly go undetected. With mild hearing HI (26-40 $\mathrm{dB})$, understanding soft conversations is difficult in the presence of background noises, like in a class room. Moderate (41-55dB) HI results in difficulty in understanding speech and higher volume is required for hearing television and radio. With moderate to severe HI $(56-70 \mathrm{~dB})$ and severe HI $(71-90 \mathrm{~dB})$, group conversations become gradually difficult and comprehension is impossible without amplification. With profound $\mathrm{HI}$ (91 dB and greater) it is difficult or impossible to hear and understand, even with amplified speech or devices.

HI can be unilateral or bilateral. In children up to 14 years, WHO defines 'disabling HI' as HI greater than $30 \mathrm{~dB}$ in the better hearing ear, when $\mathrm{HI}$ is bilateral and asymmetrical ${ }^{2}$. With advancement in technology, many cases of HI are either reversible or correctable, but early intervention is important to minimise the impact on the quality of life ${ }^{1}$. 
There is no HI screening programme for Sri Lankan school children at present. Routine hearing assessment is done in babies born at a few private hospitals, but in the government sector screening is done only in babies with identifiable risk factors for HI like prematurity, jaundice, birth asphyxia, treatment with ototoxic medication etc.

Routine screening for HI requires expensive and sophisticated equipment, plus trained technicians. Thus, an island-wide screening programme will have a significant impact on the health budget. Knowing the prevalence of HI among Sri Lankan school children is essential to analyse the cost effectiveness of such a programme. Globally, HI data are particularly sparse and Sri Lanka is not an exception. This is due to significant logistic difficulties encountered in collection of HI data, such as a quiet setting for the testing ${ }^{6}$.

\section{Objectives}

To describe the prevalence of HI among Sri Lankan school children and to assess the feasibility and effectiveness of a screening programme.

\section{Method}

A descriptive cross-sectional study was conducted in the Gampaha district of Sri Lanka. Gampaha district extends over a land area of 1387 sq. km, with a population density of 1654 persons/sq. $\mathrm{km}^{7}$. The district is divided into four educational zones: Negombo, Kelaniya, Minuwangoda, and Gampaha. From these four zones, mixed schools having both Sinhala and Tamil medium students were selected. Thirty-eight clusters, with randomly selected 25 to 30 students in each cluster were identified. The number of clusters from each zone was decided on the size of eligible student population belonging to them. A total of 985 children studying in grades two to five were recruited for the study.

A self-administered questionnaire filled by parents was used to obtain socio-demographic data and concerns about $\mathrm{HI}$ in their children. Responses to concerns about HI in children individually were obtained from the class teacher as well. All children recruited for the study were screened for $\mathrm{HI}$ at the school premises. The testing was carried out in a quiet room during school hours to minimize the effects of external noises. Children were taken out of class rooms individually. Otoscopy, pure tone audiometry (PTA) and otoacoustic emission (OAE) were employed during screening. Otoscopy was used to examine the external ear and tympanic membrane. OAE, a sensitive tool in hearing screening, was carried out using AuDx Pro OAE Screener. AudioScope 3"Rion" portable audio screener was used for pure tone audiometry. Equipment was calibrated according to the American National Standard
Institute (ANSI) standards prior to screening. Around 20-30 minutes was required to screen one child.

Children who failed one or more of the screening tests were invited to undergo the confirmatory test (PTA), which was carried out at the sound-proof audiology laboratory of the Faculty of Medicine, University of Kelaniya. Otoscopy was performed prior to PTA, to evaluate the external ear and the tympanic membrane. PTA was carried out using Grason-Stadler GSI-61 audiometer, calibrated according to ANSI standards.

Speech audiometry was performed using Sinhala/Tamil spondee words and a phonetically balanced word list via head phone stimulation. Tympanometry and reflexometry were conducted with the inter-acoustics middle ear analyser AT235h. Tympanometry assessed the functioning of the tympanic membrane. Reflexometry was performed to analyse the middle ear reflex function, as a verification tool for the results of PTA.

Results of the confirmatory tests were explained to parents. Children confirmed to have HI were referred for appropriate interventions. Children who failed the screening but defaulted the confirmatory test were reminded by post as well as through telephone, explaining the importance of undergoing the confirmatory test. Results were analysed with SPSS version 20.

Ethical issues: Ethical clearance to conduct the study was obtained from Research Ethics Committee of the Faculty of Medicine, University of Kelaniya (Registration No: F/G/S/05/02/13/2012/02). Information about child's hearing was revealed only to parents, and we advised them to disclose it to school authorities at their own discretion. Minimal interference was done to school activities during conduct of the study. Prior to the study, objectives and the procedure involved were explained to the parents. Informed written consent from parents and written permission from school authorities were obtained.

\section{Results}

Out of 984 children recruited 519 were boys and 475 were girls. Age distribution of children is given in Table 1.

Table 1: Age distribution of study population

\begin{tabular}{|c|c|}
\hline Age & Number of children (\%) \\
\hline 7 years & $284(28.9)$ \\
\hline 8 years & $235(23.9)$ \\
\hline 9 years & $292(29.6)$ \\
\hline 10 years & $173(17.6)$ \\
\hline Total & $984(100)$ \\
\hline
\end{tabular}


Main spoken language was Sinhala in $844(85.8 \%)$ children and Tamil in $140(14.2 \%)$ children. Out of 984 children recruited initially, $270(27.4 \%)$ failed one or more screening tests. Of this, $154(57.0 \%)$ failed PTA screening, with 58 having bilateral and 96 having unilateral involvement. Out of 154 children who had abnormal PTA, 133 (86.4\%) had abnormal OAE as well. PTA was negative but OAE was positive in 24 children. Thus, out of children who failed the screening, 178 (65.9\%), had abnormal PTA or OAE results. The rest had abnormal otoscope findings. All children suspected of HI either by parents or teacher, failed one or more screening tests.

Out of 270 children invited for the diagnostic testing, only 199 (73.7\%) turned up. Thus the effective number of children who completed the study was 913/984 (92.8\%). However, all children suspected of having HI either by parents or class teacher, were presented for the confirmatory tests.
Out of 199 children who underwent diagnostic testing, $40(20.1 \%)$ children were diagnosed to have minimal to profound HI. Assuming all children who failed screening attended diagnostic test and same positive rate of $20.1 \%$ prevailed in them, there would have been 54 children with confirmed HI. This would give a corrected HI prevalence of $5.5 \%$ for the total study population.

Out of 40 children who were detected having HI, $32(80 \%)$ had minimal or mild HI. Three $(7.5 \%)$ had severe and three (7.5\%) had profound HI, which is $0.66 \%$ out of the total study population. Breakdown of children according to the degree of $\mathrm{HI}$ is depicted in Table 2. Some children had asymmetrical, bilateral HI. In these children $\mathrm{HI}$ is depicted in the table according to the worse affected ear. Foot note gives the hearing level in the other ear. Overall, 18 (45\%) had bilateral HI, but only $11(27.5 \%)$ had both ears equally affected.

Table 2: Breakdown of children according to the type of hearing impairment (HI)

\begin{tabular}{|l|c|c|c|c|}
\hline \multicolumn{1}{|c|}{ Type of HI } & $\begin{array}{c}\text { Mainly or only } \\
\text { right ear affected }\end{array}$ & $\begin{array}{c}\text { Mainly or only left } \\
\text { ear affected }\end{array}$ & $\begin{array}{c}\text { Right and left ears } \\
\text { equally affected }\end{array}$ & Total \\
\hline Minimal & 06 & 06 & 05 & 17 \\
\hline Mild & $05^{*}$ & $05^{* *}$ & 05 & 15 \\
\hline Moderate & 00 & 00 & 01 & 01 \\
\hline Moderate - severe & $01+$ & 00 & 00 & 01 \\
\hline Severe & $02 \#$ & $01 \# \#$ & 00 & 03 \\
\hline Profound & $01 \uparrow$ & $02 \dagger \dagger$ & 00 & 03 \\
\hline Total & 15 & 14 & 11 & 40 \\
\hline
\end{tabular}

*2 had normal hearing on left and 3 had minimal HI on left; **3 had normal hearing on right and 2 had minimal HI on right; + normal hearing on left; \# one moderate and one minimal HI on left; \#\# normal hearing on right; † normal hearing on left; †† normal hearing on right

Out of 40 children diagnosed with HI, only four $(10 \%)$ were suspected of having HI by the teacher. Out of nine children suspected by class teacher of hearing loss, only four (44.4\%) had the diagnostic test positive. Table 3 depicts the comparison of teacher assessment versus diagnostic test results.

Table 3: Comparison of teacher assessment versus confirmatory test result

\begin{tabular}{|l|c|c|c|}
\hline \multicolumn{1}{|c|}{ Teacher assessment } & Confirmed positive & Confirmed negative & Total \\
\hline Hearing impairment (HI) suspected & 04 & 05 & 09 \\
\hline HI not suspected & 36 & 868 & 904 \\
\hline Total & 40 & 873 & 913 \\
\hline
\end{tabular}

Therefore, teacher's assessment has a sensitivity of $10 \%$ and specificity of $99.4 \%$ in detecting a $\mathrm{HI}$ in a student. Predictive value of positive teacher assessment was only $44.4 \%$.
Out of 51 children suspected by parents, 18 $(35.3 \%)$ were confirmed having HI. Table 4 depicts the comparison of parent assessment versus diagnostic test result.

Table 4: Comparison of parent assessment versus confirmatory test result

\begin{tabular}{|l|c|c|c|}
\hline Parent assessment & Confirmed positive & Confirmed negative & Total \\
\hline Hearing impairment (HI) suspected & 18 & 33 & 51 \\
\hline HI not suspected & 22 & 840 & 862 \\
\hline Total & 40 & 873 & 913 \\
\hline
\end{tabular}


Out of 40 children diagnosed with HI, only 18 $(45 \%)$ were identified by parents. Thus parental assessment of HI has a sensitivity of $45 \%$ and specificity of $96.2 \%$. The positive predictive value of parent assessment was $35.3 \%$.

\section{Discussion}

HI causes a significant negative impact on the quality of life of a child. Apart from interfering with normal language development, it will limit the child's ability of achieving maximum overall educational potential. A child with $\mathrm{HI}$ often faces difficulties at home and school, because of noncomplying with instructions and poor school performances. Therefore, early restoration of a child's hearing would make a world of difference to the child's future life. There is ample evidence in medical literature, proving academic under achievement by hearing impaired children. According to Dalebout $\mathrm{S}$, et $a l^{8}$, even unilateral involvement adversely affects the school grades of children with HI compared to normal children. They found school grades to be ten times lower in them compared to normal children. According to Powers $\mathrm{S}^{9}$, reading is one of the most affected academic activities among children with HI. Hearing-impaired students achieved only one third reading capacity compared to their hearing peers. Interestingly the other main academic area affected by HI was mathematics.

With advancement of technology, effective and safe interventions are now available to restore hearing in children. Early detection of HI may prevent further deterioration, when the cause is a correctable one, such as chronic serous otitis media. Early detection will also minimise the impact on social activities and education achievements. Olusanya $\mathrm{B}$, et $a l^{10}$, have stressed the impact of HI on functional development and educational attainment of school children, especially in developing countries. Their research highlighted the need for early intervention and the importance of collaboration among professionals. A strong relationship is also demonstrated between early intervention for $\mathrm{HI}$ and future academic and social performances ${ }^{11}$.

One would expect parents and teachers to pick up a child with HI early, because a child spends most of their time with them. However, this study indicates that only a very small percentage of children with HI are picked up by them. Surprisingly, even children with profound HI were missed by parents and teachers. HI should be considered in any child with poor academic performance. Unfortunately poor academic performance is often attributed to laziness, inattentiveness and low intelligence so that HI is overlooked. Therefore unless detected by a screening programme, some children with $\mathrm{HI}$ are likely to go undetected into adult life.

According to our study, an estimated $5.5 \%$ of children in the Gampaha district suffer from different degrees of HI. Considering the better socio-economic conditions in Gampaha district compared to other areas of the country ${ }^{7}$, we can deduce that the national prevalence of HI among school children to be similar or worse. Due to the dearth of information on $\mathrm{HI}$ in children, it is difficult to compare this figure with most other countries. In US the prevalence of $\mathrm{HI}$ at birth is $0.33 \%$, which increases to around $1 \%$ by school age due to acquired causes ${ }^{3}$. The prevalence of $\mathrm{HI}$ among Sri Lankan school children is significantly higher than US, but almost similar to global HI prevalence of $5.3 \%$ at all ages ${ }^{2}$. Therefore prevalence of HI amongst Sri Lankan school children should be lower than children from other South Asian countries ${ }^{2}$. Sri Lankan figures for $\mathrm{HI}$ at birth are not available. Therefore it is not possible to ascertain the relative contribution of congenital and acquired causes towards HI.

Sri Lanka, though a low middle income country, enjoys health statistics on par with developed countries. Maternal mortality of 29 per 100,000 births, perinatal mortality of 5.9 per 1000 live births, infant mortality rate of $8.2 \%$ per 1000 live births and immunization coverage of $98 \%$ are examples $^{12}$. These remarkable statistics are achieved through many successful public health activities. Considering the efficiency and success of other public health programmes, implementing a HI screening programme should not be difficult in Sri Lanka. Screening for $\mathrm{HI}$ can be easily conducted at child welfare clinics (CWCs), which are conducted by Medical Officer of Health (MOH) offices around the country. As children aged three years and five years are brought for immunization to these clinics, it will be the ideal opportunity to screen children for HI.

Main limitations in implementing such a programme are constraints on resources like instruments and trained personnel. As Sri Lanka is now producing trained BSc graduates in audiology, manpower should not be an issue. Though instruments and equipment needed for screening are expensive, they are portable, so that one set of instruments could cover a significant geographical area. Coupling the screening with CWCs will improve the compliance and cost effectiveness. A primary survey to assess the cost and the cost effectiveness of such a programme is warranted. We hope and wish that a screening programme for HI will be launched in Sri Lanka soon, so that around $5 \%$ of the children who suffer in 'silence' will be benefitted. 


\section{Conclusions}

In this student population in the Gampaha district, prevalence of all types HI was $5.5 \%$. The HI was mild in $80 \%$, severe in $7.5 \%$ and profound in $7.5 \%$.

\section{Acknowledgements}

We acknowledge receipt of a research grant from the University of Kelaniya, Sri Lanka to cover the expenses of the study. We also thank teachers and school authorities for the cooperation rendered to us during the study.

\section{References}

1. Eiserman WD, Shisler L, Foust T, Buhrmann J, Winston R, White K. (). Updating hearing screening practices in early childhood settings. Infants and Young Children 2008; 21(3):186-93. https://doi.org/10.1097/01.IYC.000032454 8.54693.fc

2. World Health Organization. (2012). Mortality and burden of diseases and prevention of blindness and deafness. Available at:

www.who.int/pbd/deafness/WHO_GE_H

L.pdf. Last viewed on 05.09.2018.

3. American Speech-Language-Hearing Association. Guidelines for audiology services in the schools. Guidelines for audiology services in the Ad Hoc Committee on Service Delivery in the Schools American Speech-LanguageHearing Association 1993; 35(3 Suppl. 10): 24-32.

4. Report of the Informal Working Group on Prevention of Deafness and Hearing Impairment Programme Planning, Geneva, 18-21 June 1991. Geneva: World Health Organization. Available at:

http://www.who.int/iris/handle/10665/588

39 World Health Organization. (1991). Last viewed on 16.09.2018.

5. Clark JG. Uses and abuses of hearing loss classification. American SpeechLanguage-Hearing Association 1981; 23(7): 493-500.
6. Stevens G, Flaxman S, Brunskill E, Mascarenhas M, Colin D. Mathers M, et al. Global and regional hearing impairment prevalence: an analysis of 42 studies in 29 countries. Global Burden of Disease, Hearing Loss Expert Group. European Journal of Public Health 2013; 23(1): 146-52.

https://doi.org/10.1093/eurpub/ckr176

PMid: 22197756

7. Department of Census and Statistics Sri Lanka. (2012). Census of Population \& Housing, 2011.

8. Dalebout S, Martinez EA. (2002). Facts and information about hearing impairment, Encyclopaedia of Education, (1-4). Available at:

http//www.encyclopedia.com/doc/1G23403200286.html>

9. Powers S. (2007). The educational attainments of deaf pupils: a discussion paper on data currently available. The British Association of Teachers of the Deaf. Available at:

http://www.batod.org.uk/index.php?id=/ar ticles/research/nat-data.htm

10. Olusanya B, Okolo AA, Adeosun AA. Predictors of hearing loss in school entrants in a developing country. Journal of Postgraduate Medicine 2004; 50(3): 173-9.

11. Majid S, Rehman S. The effect of early diagnosis of hearing loss on school performance of children. Sri Lanka Journal of Social Sciences 2015; 38(2): 107-15.

https://doi.org/10.4038/sljss.v38i2.7396

12. Sri Lanka Demographic and Health Survey 2016 - Department of Census and Statistics and Ministry of Health, Nutrition and Indigenous Medicine Department, Sri Lanka - 2017. Available at: www.statistics.gov.lk 